This is the accepted manuscript of the article, which has been published in Child Care in Practice. 2018, 24(3), 258-272.

https://doi.org/10.1080/13575279.2017.1391748

\title{
Familiarity or not: children's choice of interviewer in a study of substitute care
}

Helavirta, Susanna, Laakso, Riitta \& Pösö, Tarja

\begin{abstract}
This article is based on a study of children's experiences of being in care in which children were given the opportunity to choose either their own social worker or an outside researcher to interview them for the purposes of the research. The starting point of the study was that children's views are necessary to inform child welfare research and practice. However, as the topic is sensitive, there is a need to give children different options to participate in research. In this article, we examine how the children $(\mathrm{N}=17)$ describe their choice of interviewer and also explore how the social workers $(\mathrm{N}=8)$ experience their role as research interviewers.

The findings highlight that there is no single reason for children for choosing either a social worker or a researcher to be the interviewer. Familiarity in particular can either be a motivation or an obstacle. The dual positions of children as research interviewees and as clients as well as the dual positions of social workers both supported and hindered the interviews. Social workers reported new insights into their knowledge about children's views as a result of the research interview experience. It is argued that the choice of the interviewer may be an option for some children to have their voice heard in research. Ethical balancing and critical dialogue are also suggested as having a role.
\end{abstract}

\section{Introduction}

Sensitive issues pose a challenge for research ethics. This is especially so when very private, stressful or sacred issues are studied and when the studies focus on people who either live in vulnerable situations or are vulnerable themselves (Lee, 1993). The aim to protect people from the possible harms of research may then result in restrictions or avoidance in child welfare research: children may be approached by researchers only under very regulated conditions, if at all (Berrick et al., 2000; Parkers et al., 2015); child welfare case files are not made easily accessible for research (e.g. Hayes \& Devaney, 2004); or certain issues such as children's experiences of abuse are likely to be excluded from the agenda of research (Cater \& Øverlien, 2014; Mudaly \& Goddard, 2006). Consequently, 
issues which are seen as being "sensitive" and people who are seen as "vulnerable" are excluded from knowledge production for the sake of protection. This may be problematic from the point of view of child welfare policy and practice which need to learn about the views and experiences of those people in order to provide services to meet their needs and interests.

There is, fortunately, also an ambition to introduce sound ethical principles to overcome the variety of ethical challenges in research with and about children in vulnerable situations (e.g. Baker, 2005; Balen et. al., 2006; Bogolub \& Thomas, 2005; Fern \&Kristinsdóttir, 2011; Ellonen \& Pösö, 2011; Grahan et al., 2013; Holland et al., 2014; Holland et al., 2010; Kendrick et al., 2008; Schelbe et al., 2015; Willumsen et al., 2014). In particular, there are calls for developing sensitive research practices: how research is carried out with "vulnerable people" about "sensitive, stressful or sacred" issues becomes more important than the very debate about whether certain themes or groups of people should be excluded from research for the sake of protection (Cater \& Øverlien, 2014; Daley, 2012; Graham et al., 2013). Alternative ways to design sensitive research are needed (Chan et al., 2015).

In this article, our view of research in child welfare rests on the idea that children in vulnerable situations should be given opportunities to make decisions about the ways research is carried out. We explore one element in research practice, the choice of the interviewer, in a study about children in out-of-home care which is often seen as a sensitive research topic but also a topic which should not be silenced in child protection research (e.g. Holland, 2009; Kendrick et al., 2008). As we were aware of the ethical tensions, we wanted to implement a research design which would allow the children to make choices as to their research participation. The choice included first, the decision whether to participate or not (the standard meaning of informed consent), and second, the choice of the interviewer. The choice of the interviewer is a concrete, small yet meaningful way to enable children's involvement in making decisions about how data is produced. The choice of the interviewer does not guarantee any full ethical symmetry in research (Christensen \& Prout, 2002), but it recognises the differences among children as will be demonstrated later in this article. We will describe the rationale 
of this research design later in this article and empirically examine the choice of the interviewer. However, first we will present the thematic context of interview studies of children in out-of-home care, addressed here as 'substitute care'.

\section{Interviews with children in substitute care}

Being in care, out of one's own home, is a very personal and emotional childhood experience which may be overshadowed by experiences of shame and silence (e.g. Eronen, 2011; Farmer et al., 2013). Substitute care, at its best, may mean a considerable improvement in one's quality of life, but still the experiences are often shadowed by longing, sadness and lack of trust and sometimes even by abuse and neglect. Thus children might experience a strong need to talk about their life in care but also personal, social and cultural obstacles in talking (Leeson 2007). Recent reports of historic abuse demonstrate that some experiences of care may remain unworded and unheard for years (e.g. Sköld \& Swain, 2015).

Our interest in interviewing children in substitute care is based on the view that children's lived experiences of care should be learnt from the children themselves as other informants such as parents or professionals may only indirectly provide information about children's experiences (Unrau 2007). Yet, as in any interview study or professional interview, interaction between the interviewer and interviewee matters and the outcome of their interview is more or less a coproduction of the participants and thus not a full portrait of the lived experience as such (e.g. Holstein \& Gubrium, 1997; Korkman, 2006; Kvale, 2007). From this standpoint, research ethics becomes interwoven in the process of interaction and research methods in use. This is described by Kathryn Daley in the following extract:

“There is a place for prescriptive principles in human research ethics guidelines, and these guidelines can inform projects’ designs. But to inform researchers' practice, caring - with the researcher as care-giver and participant as cared-for - is the most ethical way to negotiate the complex 
situations which arise when conducting research with vulnerable young people.“ (Daley, 2012: 33.)

When interviews are “done” (Kvale, 2007), the contract between the interviewer and interviewee is constantly negotiated. The informed consent, for example, may require repeated negotiations during the research process as the power relations of the research evolve (e.g. Aaltonen, 2016; Holland et al., 2010; Renold et al., 2008; Thomas \& O’Kane, 1998; Willumsen et al., 2015). Children may use their own strategies to withdraw from the interview interaction or to influence it (e.g. running away, playing, changing the topic, silence) (Eskonen, 2005; Helavirta, 2011). Some researchers intentionally use strategies to encourage children to interrupt the interview whenever needed (e.g. Leeson, 2014) or choose places for interviews which provide more relaxed contexts of interview interaction (Mayall, 2000; Punch, 2002; Ross et al., 2009; Jeysingham, 2016). The child's maturity and skills to make informed decisions belong to the key issues of informed consent and research ethics with children (e.g. Graham et al., 2013; Hill, 2006a). These issues are typically examined by adults, who, as gatekeepers, decide whether the child is mature enough to make an informed choice about his/her participation in the research. With regard to sensitive issues such as being in substitute care, there are several gatekeepers - birth parents, child welfare authorities, foster parents/carers in residential institutions, ethics review boards among others whose permission is required even before the child's opinion and interest in making any choices can be consulted. Consequently, the child makes his/her choices of sharing the personal and intimate childhood experiences with research in the midst of institutional gatekeeping and power relations.

\section{The research design and data}

The study on which this paper is based - "Care order as interventions - the process view from inside" - was carried out with two social worker teams in two municipalities in Finland. These teams took care of children who had been placed in substitute care. The research aimed to open up the "black box of care" by studying children's first year in care. The study was motivated by the finding that very little is known in Finland about the immediate processes in children's 
everyday lives and institutional practices initiated by the care order decisions although the care order decision is the most intrusive decision into the rights of children and families by public authorities and thus a very particular childhood experience (see also Mitchell \& Kuczynski 2010). The start of care is marked by the care order decision, authorised by the Child Welfare Act (417/2007), which restricts parental rights and places the child in substitute care. The placement is meant to be only temporary, including annual reviews of the care plans and relevance of the decision (Pösö \& Huhtanen 2017).

As our interest was in the process after the entry into care, the prospective design included two temporal points for data collection. The first point - six months after the care order - was chosen so that it allowed the children to have had some time to settle in care before the data collection and the next point - at 12 months allowed us to see the first full year in care. The research design was developed together with the social workers of the two teams. Working with children in care can be professionally, ethically and emotionally challenging (e.g. Buckley, 2003; Forsberg \& Vagli, 2006; Lonne et al., 2016) and therefore studies on care can be experienced as an intrusion into one's professionalism; on the other hand, they may provide a welcome platform for practitioners for constructive reflection on one's work. The latter view was the starting point for this study which rests on cooperative research between the social workers and researchers. In the early stages of the planning process the issues of interviewing the children were discussed as the interviews challenge not only the ethics of research but also the procedures to gain access to children. Social workers experienced that some children might not be willing to meet an outsider - an unknown person - for an interview. This was due to personality issues, shyness for example, but also due to a feeling of jadedness as so many adults interview children: social workers, psychologists, school teachers as well as other professionals. Although such interviews are of professional and institutional nature, a new person - a researcher in this case - might feel like an extra burden for some children. The social workers thought that in general children in substitute care would be willing to share their experiences of care but should be given a choice how to do it. The choice of the interviewer was the key issue. Based on their experience in practice, they 
suggested that some children would most likely prefer to do the interview with their own familiar social worker.

When building the research design, we took these concerns and advice - also recognisable in the literature on studies with children (Hill, 2006b) - very seriously. Consequently, children were given the opportunity to choose between a researcher and a social worker. The options for the research interview were introduced by their own social worker. There was an information sheet which they looked at together when discussing the choice of the interviewer. Before that, the written permission to interview the children had been received from their parents and the social welfare agencies. In addition, the Regional Ethics Review Board at the University of Tampere had reviewed our research plan. The interviews were targeted at children who were seven years or older and who had been taken into care during a certain six (bigger municipality) and eight (smaller municipality) month period in 2013. Thirty-four children met those general criteria. When inviting the children to join the research, the social workers had to assess whether the children were in such stable situation that the interview would not harm them. Children who were in psychiatric hospital care or had experienced recent traumatic events at the time of the study, for example, were excluded from the group of invited children. The ultimate decision whom to ask was based on social workers' professional assessment. The recruitment process was concluded when the appropriate number of children was included in the research so that it was possible to interview the children twice within the time frame of the research project. The children were told, orally and in the written information sheet, that the choice of the interviewer was up to him/her. The confidentiality of the interviews was highlighted to the children as well as the fact that the research nature of the interview meant that they were separate from the other interviews in child welfare. As a result, nine children chose a social worker and eight a researcher to be the interviewer. Children were also instructed that they could choose the place for the interview - all interviews were carried out in the children's placement, either in a foster home or in the residential institution, mostly in their own room. 
As a result, the interview data includes interviews with 17 children, of whom 15 were interviewed twice. Two children were not available for the second interview as they had aged out of care at the point of 12 months after the care order.

The children were between the ages of 7 and 17, the majority of them (12) being between the ages of 14 and 17. The interview scheme in both interviews covered the issues of every-day life in care, including contact with families and social workers and quality of life in a general sense. The first interview also included topics about transition into care.

Self-evidently, an important precondition for this design was that the social workers were willing to conduct the interviews. Their agreement was established in the early parts of the process of the research. We - three researchers with $\mathrm{PhDs}$ in social work and professional experience in social work and social workers organised sessions to discuss the aims, methods and ethics of the interview study. In particular, we discussed ethics in a situation in which the research interviews would reveal something new and sensitive for child welfare practice. The issue of confidentiality was obviously a complex issue from the practitioners' point of view. We agreed that the borders between research and child welfare work should be kept clear. If there was a reason to think that the information given by the child in the research interview would need institutional attention, this would then to be discussed with the child before any action. It was also decided that the social workers should not make any notes in the case files about the information gained in the interviews in order to mark the separate role of the research interview. The children were told about these principles when the interviews started. Despite the complex confidentiality, every social worker in the teams agreed to being an interviewer if the child so wished. As an MA degree is required in Finland for social workers, the interviewers had some understanding of research methods in order to carry out the interviews.

The rich data gathered in this design has provided basis for analyses published elsewhere (e.g. Pösö et al., 2015; Pösö et al. 2016; Helavirta 2016; Laakso 2016). In this article we focus on examining how the children describe their choice of interviewer. We also explore how the social workers experience their role as a research interviewer. To do that, we use two parts of the data. First, the children 
were asked in the second interview why they chose a certain interviewer. The answers - very short, a couple of sentences at most - were recorded and transcribed and used for a thematic analysis of the reasons the children gave to the choice of the interviewer. Secondly, we asked every interviewer to "think aloud" about the interview they just had finished with the child interviewee. The instruction was that they should voice-record their thoughts about the interview (e.g. whether the interview included any surprises). Eight social workers, of whom seven were women, recorded their thoughts after the first round of the interviews and seven social workers after the second round. We missed one recording in the second round as that social worker was short of time as she explained informally to the researcher afterwards. These reflections $(\mathrm{N}=15)$ lasted between five and ten minutes. They have been transcribed and thematically analysed for this paper with one main question in mind: what are the characteristics the social workers attach to the research interview. Both types of data have been thematically analysed by one research group member. In case the descriptions were difficult to understand or to thematically categorise, they have been discussed by the whole team.

The following analysis is structured so that we first present the children's descriptions of their choices of the interviewer, categorised into four themes, after which the social workers' descriptions on conducting the research interview are presented. For reasons of confidentiality, we do not contrast the children's accounts with those of the social workers but analyse and present them separately. We call all children "children”, regardless of age, and all social workers as social workers.

\section{Limitations}

The study is very limited in terms of the number of children and child welfare agencies involved. We had the opportunity to work with two highly skilful and research minded social work teams which helped to develop among other things such a code of ethics for the interviews that met the ethical standards of practice as well. Despite the skills of the social workers and their motivation to join the research, we are not fully aware of the selection of the interviewees and possible biases, or the tensions created by the combination of practice and research. In 
particular, we lack an understanding of the impacts of the research interviews on the relationships afterwards. The interview, whether carried out by the researcher or the social worker, was inevitably an intervention into the existing relationships in the care system; unfortunately, the examination of the impacts was not included in this study. In addition, the study excluded younger children from the design, which is a shortcoming for countries with a majority of younger children in the care system. The findings do, however, highlight that children used the opportunity to choose the interviewer for their individual reasons, and therefore the findings could be used for further exploration and testing of designs recognising the differences among children.

\section{Findings}

\section{Children: who can interview me?}

The children (9) who chose a social worker as their interviewer were between the ages of 7 and 17 while those children (8) who chose a research interviewer were 8 to 17 years old. Boys in particular (five out of six) chose the social worker to be the interviewer, which we find difficult to explain. The explanations of choosing a social worker as an interviewer fall into the following four categories of which the issue of familiarity was most important.

It is easier to talk with someone familiar

When children explained why they had chosen the social worker to be the interviewer, they mention familiarity as the important element. Familiarity was referred to in two meanings. First, it meant that the child knew the social worker as a person already before the interview as they had met previously. Secondly, children sometimes described the social workers as familiar persons even if they had not met before: the children said that the social workers would know their “case” anyway by reading the case files. If someone knew their "case”, it would be easy to talk. The following extracts demonstrate how familiarity was taken for granted as a reason; it did not need much exploration. 
Well because it is easier for me to speak with someone I know. (Pekka)

Of course it is nicer when it is someone whom you have met before and who knows my situation. (Anna)

\section{Familiarity as an obstacle}

Sometimes familiarity was seen as being an obstacle for an interview, and therefore the social worker was not chosen. Someone said that "the social worker is so familiar" and chose a researcher to be the interviewer. For him, familiarity was an obstacle as it was for the other child in the following extract.

I thought that I would rather take someone unknown, it is easier to speak to a stranger about things. (Jani)

More detailed descriptions of why familiarity would be an obstacle were rare. One child referred to her earlier negative experiences with that specific social worker. As she was given the opportunity to speak with someone else, she chose a person who did not know her and with whom she did not have any shared history of conflicts.

\section{The institutional role of the social worker}

Children reported that social workers have the rights and duties to make decisions about children's lives. These institutional tasks were the reasons why some children chose a researcher: the researcher would not use the information of the interviews when making institutional decisions. Talking with a social worker would be more limited as the child would need to control what was said. Some children expressed concerns that the social workers could use information against their own wishes later.

Because she makes decisions about my things, so I would like to speak with someone else. (Eeva)

The social worker can use my stories against me. (Sonja) 
A child mentioned the social worker's institutional tasks in a very different meaning: she was concerned about the social worker's use of time. If she chose the researcher, her social worker would have more time to work with other children.

So that the social worker has time to go somewhere else, to help other children. (Mari)

\section{It did not matter}

When asked about the reasons to choose a certain type of a person to be the interviewer, some children replied "I do not know", "it did not matter" or "I do not remember”. Their answers demonstrate that the interviewer was not very important or that it was difficult to remember anymore why the choice had been made in a certain way. They also demonstrate some reluctance to give any report about the reasons.

\section{Social workers: balancing between the roles of a researcher and a worker}

When social workers "thought aloud" about the research interview from their point of view, the descriptions can be grouped under three main themes: shifting positions, learning new things about children and children as information gatekeepers. The reflections after the first and second interviews did not differ between each other.

\section{Shifting positions}

The social workers pointed out that it was not always easy to fit a research interview into their busy social work schedule. It was also difficult to find the "right" mode to interview a child for a research interview. The first extract below describes the shifts which the social worker had to go through when starting the research interview with a child. The emotional landscape of child welfare overshadowed the start of the interview; nevertheless, the interview was properly done, as noted by the interviewer. The second extract highlights the continuum in child welfare: the interview cannot be cut off from the previous events in child welfare. 
I went there to the interview situation from a very difficult meeting in which we had to make quite difficult decisions. I was a bit concerned whether I could calm down for this interview. (Katja)

I have a rather good feeling; before I was a bit worried about the thoughts that will turn up, when the girl thinks of the situation now, when she has gone to that place, transferred from another place, it has been quite something as she herself says here; so that she was at the police for a while, and then it was the men from the transport agency who took her. I thought that there could be something; I got this girl only in January, but it was nice now to do this interview so that we learnt to know each other. (Maarit)

The social workers reported that they positioned themselves as listeners and learners in the interview situations: they were there to learn about the child's situation and views instead of assessing the child's situation or making new plans. Sometimes the learning and listening element was strong because they had not yet met and learnt to know the child as the previous extract demonstrates.

\section{Learning new things about children}

When interviewing children according to a research interview guide, the social workers addressed themes that they did not conventionally address in their professional work with children. This was often remarked upon by the social workers. They also expressed their surprises regarding the children's narratives; they had learnt new things about the children.

One of the surprises was caused by the theme about the reasons for the care order. In the first interview round, we wanted to learn how the child described the reasons for him/her being in care and this theme was accordingly in the interview guide. This was a difficult question for most children. This surprised the social workers because they remembered that they had often discussed this theme with the child. The surprise is described in the following extract. 
The boy has been there only a year and I was surprised as a social worker that he did not have any idea, and has not spoken anything about it when I visited him a couple of times, and we have gone through the reasons for the care order several times. But these issues do not seem to be clear for the boy, or he does not admit them. (Leena)

An even more surprising event in the interviews was the episode between a social worker and a boy, 13, in which the boy asked the social worker to explain why he was in care. The boy explained that he did not know the reasons and he especially did not know why he was placed in a residential institution instead of a foster home which had been his wish. The social worker had thought that the boy was aware of all the reasons; however, the lack of knowledge was revealed in the interview.

When listening to the child's experiences of care, the social workers learned about the concerns the child had. The concerns, as mentioned in the "'think-alouds", were especially about restrictive practices and unfair treatment in alternative care. One social worker mentioned that she had learnt about such practices in a residential institution with the result that she had to sort out the poor practice with the institution. In another interview, the boy told the social worker about his experiences of abuse in his birth family. A social worker reported to us how relieved the boy seemed to be after he had told about the abuse. She describes her own position in the interview in the following way:

When this abuse turned up, it was a surprise. That is why I could not say anything. But it was good to hear that the boy was so relaxed after he had had the opportunity to tell about it. The story is that this boy was in a foster home the quality of which I am not satisfied with. It was the most surprising thing that the boy put that place as a "five"on the scale and this present home as a “ten”. I almost started to cry as I feel that the boy now, really, has been rescued. (Ulla) 
Among the positive surprises was the choice the children made in the interview to address the social worker as one of his/her important people.

It was of course that positive issue which I remember; if the social worker is counted as a trustworthy person by the child, of course it is a fine thing. It means that one has managed to create a relationship of some kind even though we have not yet met that often. (Meeri)

The surprises encountered by some social workers contrast the nature of a research interview against the professional interview. The social workers reported that the research interview gave more space for the child to tell about her/his experiences than had been enabled by the professional encounters. This is described in the following extract.

I really understood only now what it means that one should have opportunities to tell a bit more freely, that it would not only be talking in a meeting. That it should be free. That it would not be so structured but that the child could just talk. I got the feeling that now the child had the opportunity to speak more freely. (Jenni)

\section{Children as information gatekeepers}

In the social workers' view, the information which the children shared in the research interviews differed to some extent from the information known in child welfare practice. This made the social workers aware of the children's agency as gatekeepers of information as they put it. The children silenced some themes in the interviews. According to the social workers, the silenced themes were especially sad and emotionally troubling themes which they themselves had learnt to know in their institutional role. One girl, for example, had recently been raped but this was not mentioned in the interview at all. Sometimes care was described more negatively than the social worker understood it to be. One child described the substitute home as a place where nothing happened but the social worker recalled several visits to fun parks. 
He gave wrong information about the placement, that they do not do anything there. They visit many places, fun parks and such but he says not. (Marja)

He did not describe any adults in his placement as being important to him. I know, and I am told by the adults in the placement, and I see it when I visit the place, that he has a really good relationship with the place and his case worker. (Tuula)

As a consequence of the realization of children's active choice of silencing some themes, the social workers expressed their concern about the validity of children's accounts in the interviews. From their point of view, there was a discrepancy between the research interview and their institutional knowledge. As they had known the children for longer, they also remarked on the impact of the time when the interview was done. The research interview picked up only temporal fragments of children's time in care and was thus bound to provide non-permanent information.

A couple of weeks ago it was quite different and even the girl's face looked different. (Johanna)

\section{Discussion: familiarity and dual positions}

What we have seen above is that the option to choose the interviewer is actively used by some children. Other children are more nonchalant about this option or at least withdraw from reporting their reasons for choosing a particular interviewer. This may tell us something about the position of children in which the choice of the interviewer is embedded. Children meet a variety of professionals, many of them interviewing children for institutional reasons, and when asked to make a choice for a research interviewer, the choice may appear to be difficult or meaningless. The children's position in adult-led situations does not necessarily encourage them to ask questions and therefore their very informed choice may be limited. 
When making and reporting active choices, the familiarity of the interviewer plays an important role as was expected at the beginning of the research process. When familiarity is positively important, the interview is "easier" for the child as described above; the fact that the social worker knows the child is seen as strength. As we know based on the literature presented earlier, that being in care may be a sensitive issue, it is important that there is a way to make it "easy" for the child to enter the interview relations. Familiarity may lower the threshold for sharing one's experiences in care as the interviewer knows the background already, and it may lessen the experiences of (possible) shame in an interview situation. Some children used this opportunity to tell social workers more and differently than they had done in the previous institutional encounters with social workers. The boy who told about his previous experiences of abuse is a good example of this. Unfortunately the data does not allow us to explore the reasons for "telling more" in detail but one may assume that the interview scheme and the style of interaction (social workers as listeners with sufficient time) played their part. Following from what has been said above, the option to make a choice of a familiar interviewer may be a relevant precondition for a study with (some) children in substitute care.

However, familiarity is also an obstacle for some children due to the dual position of a social worker as a researcher interviewer and a practitioner. Some children wanted to be allowed to tell their views to a stranger who did not have any previous knowledge and who could not use the interview information for any institutional decision. When they chose a researcher as an interviewer, they also chose someone who could not test the validity of information in the same way as their social worker. The platform with a researcher welcomes a space without any shared history and any future implications for substitute care.

Indeed, we have seen that the formal positions of a social worker and client did not vanish in the data collection process. This was so despite the interview design positioning the interview partners differently from their ordinary positions. Children still recognised the social work interviewer in her institutional role and the social workers negotiated their roles, duties and interests as professionals in addition to those of the research interviewers. 
Due to the roles of clients and social workers, the struggles with the nature and confidentiality of interview data are interwoven in the implementation of this design despite our separation of the research interviews from the practice interviews. Every party was aware of the sensitive nature of the interviews and tried to master it in their different ways. We have seen, for example, that some children explicitly said that they did not want their social worker to know "everything" and we have seen that the social workers struggled not to use the interview information that they had learnt in their institutional capacity. Some social workers assessed the validity of information given by the children by contrasting it with the knowledge they had otherwise learnt. This is a reminder of how in practice social workers constantly make and re-make sense of knowledge to understand the case of the child they are working with (Buckley, 2003). This may - or may not - influence, intentionally or unintentionally, later relations with the child interviewed for the research as the relations between the children and social workers continued after the project.

These struggles between the different roles, positions and knowledges are not easily solved in a design such as ours. In fact, our ambition to address the ethics of research with children in care by providing children an opportunity to choose the interviewer ended up in new ethical controversies. Cham and his colleagues (2015) discuss alternatives to keeping research processes separate from or integrated in practice and present both protective and minimalist approaches. The latter aims to keep clear boundaries between research and treatment processes - as we aimed to do but the boundary was challenged in research practice. Their recommendation about ethical balancing states that

The inclusion of clients in methodological discussions could integrate knowledge related to methodological rigor with information about the way different research forms affect participants. This integration may lead to creative research approaches and the possibility of offering research participants choices of different levels of separation-integration between research and intervention processes. (Cham et al. 2015)

Following from that, we suggest that the step forward would be to integrate the findings of familiarity and dual positions into a critical dialogue of the ways in 
which different knowledges are produced (and indeed silenced) in the everyday relations in child welfare research and practice (e.g. Reynold et al. 2008). The key question as suggested by this study would then be why children tell more, less or differently about their care experiences to a practitioner in an interview for research purposes compared with an interview for professional purposes. This question challenges both child welfare as well as research practice, and it would hopefully invite social workers, children in care and researchers to address the question. In addition, it would be important to examine empirically the impacts of the integration of research and practice on the relations between children and practitioners so that the long-term impacts would become better known than in the study in question.

\section{Conclusions}

The study has highlighted that children used the opportunity of choosing the interviewer for different reasons, with familiarity of the interviewer being the key reason for or against a social worker as an interviewer. “A stranger” was the preferred interviewer option for some children. The approach of "choice” recognised children's individual interests, situations and needs, and indirectly, their different views on what "sensitivity" means in research on care experiences.

As a result, we suggest that there could be some potential in exploring the element of choice in sensitive research with children and in developing practices of ethics so that children are given the positions to make more choices in their research involvement. Similar issues are addressed in designs of participatory and serviceuser-led research with children (e.g. Horgan, 2016). Our study highlights that even a "small" choice could matter and facilitate some children's participation in the research. This potential could be explored more if we distance ourselves from over-sensitivity towards ethical matters in research with and about children (Solberg, 2014; Horgan 2016) and balance wisely the children's right to be included in research against the right to be protected from research. The most important argument would, however, be that the policy and practice of research ethics should recognise the differences among children - not only their difference 
from adults (Hill, 2006b). In this way we could acknowledge the different interests and ambitions the children have in joining a research interview. An even more complex issue is, however, how to do it in such an institutional context as child welfare, which, to some extent, determines the positions and agency of children. The complexities and ethical controversies for children and practitioners have been highlighted in this study, resulting in the suggestions about ethical balancing and critical dialogue. Self-evidently, alternative and more detailed suggestions for sustainable research designs are still needed.

\section{References}

Aaltonen, S. (2016). Challenges in gaining and re-gaining informed consent among young people. on the margins of education. International Journal of Social Research Methodology. DOI 10.1080/13645579.2016.1170412

Balen, R., Eric, B., Calabretto, H., Fraser, C., Horrocks, C. \& Manby, M. (2006). Involving children in health and social research, 'human becomings' or 'active beings'? Childhood 13 (1), 29-48.

Baker, H. (2005). Involving Children and Young People in Research on Domestic Violence and Housing. Journal of Social Welfare and Family Law 27 (3-4), 281-297.

Berrick, J., Duerr, F. \& Fox, A. (2000). Assessing children's experiences of outof-home care: Methodological challenges and opportunities. Social Work Research 24 (2), 119-127.

Bogolub, E. \& Nigel, T. (2005). Parental Consent and the Ethics of Research with Foster Children. Qualitative Social Work 4(3), 271-292.

Buckley, H. (2003). Child Protection Work. Beyond the Rhetoric. London: Jessica Kingsley. 
Cater, Å. \& Øverlien, C. (2014). Children exposed to domestic violence: a discussion about research ethics and researchers' responsibilities. Nordic Social Work Research 1(4), 67-79.

Chan, S., Teram, E., \& Shaw, W. (2015). Balancing Methodological Rigor and the Needs of Research Participants: A Debate on Alternative Approaches to Sensitive Research. Qualitative Health Research DOI: 10.1177/104973231560272

Christenssen, P. \& Prout, A. (2002). Working with Ethical Symmetry in Social Research with Children. Childhood 9(4), 477-497.

Daley, K. (2012). Gathering sensitive stories. Youth Studies Australia 31(3), 2734.

Ellonen, E. \& Pösö, T. (2011). Children's Experiences of Completing a ComputerBased Violence Survey: Ethical Implications. Children \& Society 25 (6), 470481.

Eronen, T. (2011). Three Stories about Mother - narratives by women who have lived in care. Child \& Family Social Work 17(1), 66-74.

Eskonen, I. (2005). Violence in Children's Narration. The International Journal of Child and Family Welfare 8(1), 32-45.

Farmer, E., Selwyn, J. \& Meakings, S. (2013). 'Other children say you're not normal because you don't live with your parents'. Children's views of living with informal kinship carers: social networks, stigma and attachment to carers. Child and Family Social Work 18(1), 25-34.

Fern, E. \& Kristinsdóttir, G. (2011). Young people act as consultants in childdirected research: an action research study in Iceland. Child and Family Social Work 16(3), 287-297. 
Forsberg, H. \& Vagli, Å. (2006). The social construction of emotions in child protection case-talk. Qualitative Journal of Social Work 5 (1), 9-31.

Graham, A., Powell, M., Taylor, N., Anderson, D. \& Fitzgerald, R. (2013). Ethical Research Involving Children. Florence: UNICEF Office of Research - Innocenti.

Hayes, D. \& Devaney, J. (2004). Accessing Social Work Case Files for Research Purposes: Some issues and problems. Qualitative Social Work 3(3), 313-333.

Helavirta, S. (2011). Home, children and moral standpoints: a case study of child clients in child welfare. Qualitative Social Work 10(4), 434-450.

Hill, M. (2006a). Ethical considerations in researching children's experiences. In S. Greene \& D.Hogan (Eds), Researching children's experience. Approaches and Methods. (pp.61-86). London,Thousand Oaks and New Delhi: Sage.

Hill, M. (2006b). Children's voices on ways of having a voice. Children's and young people's perspectives on methods used in research and consultation. Childhood 13(1), 69-89.

Holland, S., Williams, A. \& Forrester, D. (2014). Navigating ethical moments when researching substance misuse with parents and their children. Qualitative Research 14 (4), 411-427.

Holland, S., Renold, E., Ross, N. \& Hillman, A. (2010). Power, agency and participatory agendas: A critical exploration of young people's engagement in participative qualitative research. Childhood 17 (3), 360-375.

Holland, S. (2009). Listening to Children in Care: A Review of Methodological and Theoretical Approaches to Understanding Looked after Children’s Perspectives. Children \& Society 23 (3), 226-235

Holstein, J. \& Gubrium, J. (1997). Active Interviewing. In D. Silverman (Ed.), Qualitative Research. Theory, Method and Practice (pp.113-130). London: Sage. 
Horgan, D. (2016). Child participatory research methods: Atemmpts to go ‘deeper’. Childhood. DOI: 10.1177/0907568216647787

Jeyasingham, D. (2016). Place and the uncanny in child protection social work: Exploring findings from an ethnographic study. Qualitative Social Work doi: 10.1177/1473325016657867 .

Kendrick, A., Steckley, L. \& Lerpiniere, L. (2008). Ethical issues, research and vulnerability: gaining the views of children and young people in residential care. Children’s Geographies 6 (1), 79-93.

Korkman. J. (2006). How (not) to Interview Children: Interviews with Young Children in Sexual Abuse Investigations in Finland. Turku: Åbo Academy University.

Kvale, S. (2007). Doing interviews. London: Sage.

Lee, R. (1993). Doing Research on Sensitive Topics. London: Sage.

Leeson, C. (2014). Asking difficult questions: exploring research methods with children on painful issues. International Journal of Research \& Method in Education 37 (2), 206-222.

Leeson, C. (2007). My life in care: experiences of non-participation in decisionmaking processes. Child \& Family Social Work 12 (3), 268-277.

Lonne, B., Harries, M., Featherstone, B. \& Gray, M. (2016). Working Ethically in Child Protection. London: Routledge.

Mayall, B. (2000). Conversations with children. Working with Generational Issues. In P.Christensen \& A.James (Eds), Research with children. Perspectives and Practices (pp. 109-123). London \& New York: Routledge. 
Mitchell, M. \& Kuczynski. (2010). Does anyone know what is going on?

Examining children's lived experience of the transition into foster care. Children and Youth Services Review 32, 437-444.

Mudaly, N. \& Goddard, C. (2006). The Truth is Longer than a Lie. Children's Experiences of Abuse and Professional Interventions. London: Jessica Kingsley Publishers.

Parkers, A., Shore, C., O’Mahony, C. \& Burns, K. (2015). The rights of the child to be hear? Professional experiences of child care proceedings in the Irish district court. Child and Family Law Quarterly 26(4), 423-444.

Punch, S. (2002). Interviewing Strategies with Young People: the "Secret Box", Stimulus Material and Task-based Activities. Children and Society 16(1), 45-56.

Pösö, T., Helavirta, S. \& Laakso, R. (2015). Time in care: the first months in care. Families, Relationships and Societies. http://dx.doi.org/10.1332/204674315X14501122985334

Pösö, T., Pekkarinen, E., Helavirta, S. \& Laakso, R. (2016). "Voluntary" and "involuntary" child welfare: challenging the distinction. Journal of Social Work. DOI: $10.1177 / 468017316653269$.

Pösö, T. \& Huhtanen, R. (2017) Removals of children in Finland: a mix of voluntary and involuntary decisions. In K. Burns, T. Pösö \& M. Skivenes (eds) Child welfare removals by the state: A cross-country analysis of decision-making systems (pp.18-39). New York: Oxford University Press.

Renold, E., Holland, S., Ross, N. \& Hillman, A. (2008). 'Becoming Participant' Problematizing 'Informed Consent' in Participatory Research with Young People in Care. Qualitative Social Work 7(4), 427-447. 
Ross, N., Renold, E., Holland, S. \& Hillman, A. (2009). Moving stories: using mobile methods to explore the everyday lives of young people in public care. Qualitative Research 9(5),605-623.

Schelbe, L., Chanmugam, A., Moses, T., Saltzburg, S., Rankin, L. \& Letendere, J. (2015). Youth participation in qualitative research. Challenges and possibilities. Qualitative Social Work 14 (4), 504-521.

Sköld, J. \& Swain, S. (Eds). (2015). Apologies and the Legacy of Abuse of Children in 'Care'. Basingstoke: Palgrave Macmillan.

Solberg, A. (2014). Reflections on interviewing children living in difficult circumstances: courage, caution and co-production. International Journal of Social Research Methodology 17 (3), 233-248.

Thomas, N. \& O’Kane, C. (1998). The Ethics of Participatory Research with Children. Children and Society 12(5), 336-348.

Unrau, Y. (2007). Research on placement moves: Seeking the perspective of foster children. Children and Youth Services Review 1(29), 122-137.

Willumsen, E., Hugaas, J. \& Studsrød, I.(2014). The Child as Co-researcherMoral and Epistemological Issues in Childhood Research. Ethics and Social Welfare 8(4), 332-349. 